\title{
Abota A lógica produtiva da publicidade num conto de Primo Levi ${ }^{1}$
}

THE PRODUCTIVE LOGIC OF ADVERTIIING IN A SHORT STORY BY PRIMO LEVI

\section{João Anzanello Carrascoza}

Doutor (2003) e mestre (1999) em Ciências da Comunicação pela Escola de Comunicações e Artes da Universidade de São Paulo, onde é professor. Docente do Programa de Pós-Graduação em Comunicação e Práticas de Consumo da ESPM-SP, com pós-doutorado (2014) pela Universidade Federal do Rio de Janeiro. E-mail:

jcarrascoza@espm.br

Recebido em 3 de fevereiro de 2015. Aprovado em 26 de junho de 2015.

\section{Resumo}

O discurso da publicidade contemporânea vem se capilarizando cada dia mais pelos meios de comunicação de massa e se adaptando a novas plataformas midiáticas. Sua lógica de produção se espalha por outros tipos de textualidades difundidas pelas mídias e se sedimenta como uma forma de publicização da vida cotidiana. À semelhança de outros estudos que temos empreendido, vamos investigar, por meio de um texto de ficção da literatura mundial, aspectos do consumo e da retórica da propaganda ${ }^{2}$. Desta vez, escolhemos, o conto "Escrito na testa", do italiano Primo Levi. Conceitos da Análise do Discurso de linha francesa, da teoria literária e da linguagem publicitária serão mobilizados em nossa discussão - levando-nos a compreender, através desta narrativa ficcional, a estratégia de espraiamento da publicidade contemporânea.

Palavras-chave: Consumo. Literatura. Publicidade.

1 Versão revista do trabalho apresentado no XII Congreso Latinoamericano de Investigadores de la Comunicación - Alaic, realizado na Facultad de Ciencias y Artes de la Comunicación, Lima, Peru, de 6 a 8 de agosto de 2014

2 Pesquisa financiada pelo CAEPM - Centro de Altos Estudos da ESPM. 


\section{Abstract}

The discourse of contemporary advertising increasingly disseminates itself in the means of mass communication and adapts itself to the new media platforms. Its production logic spreads itself throughout other types of textualities, which are propagated by the media and it consolidates itself as a form of publicisation of everyday life. As we did in some other studies, we will investigate aspects of consumption and of advertising rhetoric by means of a fictional text of world literature. This time we chose the short story "Written on the Forehead", by the Italian writer Primo Levi. We will mobilise concepts of French Discourse Analysis, of literary theory and of the language of advertising - which leads us to discuss the dissemination strategy of contemporary advertising by means of the fictional narrative in question.

Keywords: Consumption. Literature. Advertising.

\section{A publicidade objetivada no corpo humano}

Por meio dos objetos, sejam bens de consumo ou não, também nos comunicamos. "Tornamos comum", por meio de nossa relação com os objetos, o que pensamos e sentimos sobre o mundo e a nossa condição. Ao utilizarmos um objeto ou consumirmos uma mercadoria - a sua materialidade e a sua dimensão simbólica, como num anúncio -, estamos produzindo sentidos sobre nós, entre eles a nossa posição social.

O consumo é um código que traduz relações sociais e, uma vez que os meios de comunicação de massa adquiriram preemência na sociedade nas últimas décadas, neles, como afirmam Douglas e Isherwood (2006, p. 16), esse código tem a sua "dimensão ampliada".

A publicidade faz circular continuamente seu discurso pelos espaços midiáticos, incitando o indivíduo a crer no mundo de satisfação que ela constrói, e, a cada dia mais, utilizando-o - queira ele ou não - como mídia de produtos. Carlos Drummond de Andrade (1984) explicitou esse processo no seu já clássico poema "Eu, etiqueta": por meio da roupa que usa, e demais produtos que consome, o homem se torna "homem-anúncio itinerante/ escravo da matéria anunciada". Em vez de ser "anúncio contratado", ele é quem paga para anunciar e vender. Não lhe convém o título de homem, mas de coisa. Drummond encerra o poema com o verso "Eu sou a Coisa, coisamente", sinalizando, em letra maiúscula, a condição dominante da Coisa sobre o homem.

Ainda assim, em "Eu, etiqueta", o indivíduo cede apenas seu corpo como um meio de difusão do discurso publicitário - que se consubstancia "em língua nacional ou em qualquer língua/ (qualquer, principalmente)". A publicidade adere ao seu corpo, feito uma roupa que ele pode vestir e despir quando quiser, sem que sua integridade física seja maculada. 
No conto "Escrito na testa", de Primo Levi, como o título prenuncia, os tentáculos da publicidade vão mais longe, cravam-se na pele do homem, no espaço em branco de sua fronte. A mensagem comercial não segue numa camiseta, da qual o indivíduo pode facilmente se livrar, mas é "marcada" como se faz com o gado - já o veremos, em detalhes, a seguir. Obviamente, esse meio "desumano" é a mensagem, conquanto também ela é inscrita na carne, lesando o meio que a promove.

Aspectos vários da lógica de produção da publicidade, de sua apropriação das tecnologias para promoção e consumo não apenas de seus produtos - mas, sobretudo, de seu ideário - e de suas estratégias suasórias serão enfatizados aqui, a partir dessa "espantosa" peça literária. Antes, é essencial contextualizá-la em conjunção com a vida e a obra de seu autor.

\section{Primo Levi e o homem condenado a ser homem}

Filho de judeus, Primo Levi nasceu em 1919 em Turim - e suicidou-se em 1987. Ainda jovem e, formado em química, juntou-se em 1943 a um grupo ligado ao movimento Giustizia e Libertà, que combatia o nazifascismo. Em pouco tempo, contudo, foi preso pelas milícias de Mussolini e deportado para Auschwitz, onde permaneceu até que as forças russas iniciassem a desativação daquele campo de concentração (DIAS, 2005, p. 12).

Dessa experiência arrasadora, nasceria o escritor que estrearia, em 1947, com o livro $E$ isto um homem?, um depoimento contundente sobre o horror vivido por Levi durante o seu confinamento. Embora essa seja a obra mais mundialmente celebrada do autor, e outros de seus livros, como A trégua, possam ser associados à literatura de testemunho, Primo Levi se dedicou também à prosa de ficção, publicando vários volumes de narrativas curtas, como Histórias naturais, Vício da forma (de onde extraímos o conto "Escrito na testa") e Lilith.

Sua obra contística, fortemente atravessada por elementos de fiç̧ão científica, mantém dialogo complementar com seus livros "autobiográficos", nos quais Levi rememora as atrocidades que viu e vivenciou quando prisioneiro no campo de concentração. Segundo Brombert (2001, p. 194), o próprio escritor observou na quarta capa de Histórias

naturais, "que as suas invenções não estavam dissociadas do trauma do Lager" - e essa "ponte", essa "continuidade", vale para as demais coletâneas de histórias breves que ele escreveu.

Depois de narrar, como missão humanista, de intelectual engajado, a vida em Auschwitz, Levi se enveredou literariamente pelo território do "fantástico". O que se vê em seus contos 
é precisamente a negação daquela liberdade inalienável do homem defendida com unhas e dentes nos relatos sobre a experiência no campo de concentração. Portanto, paradoxalmente, o momento da invenção não liberta o narrador de sua pesada memória, mas o remete a um campo obscuro e reprimido pela razão iluminista: [...] o campo da fatalidade biológica e da hipótese aberrante de que a espécie esteja desde sempre orientada para a autodestruição (DIAS, 2005, p. 14, grifo do autor).

Em "Escrito na testa", a degradação do homem, por meio dessa "razão" que rege o mundo capitalista, está presente no relato mediante detalhes expressivos revelados pelo narrador-observador. James Wood (2011) nos ensina que, na prosa de cunho realista, aperfeiçoada por Flaubert, a verossimilhança é garantida por detalhes que o narrador imprime na trama. Uma vez que não tem como apreender inteiramente o "real", ele o faz por pequenas partes - detalhes que exprimem a ideia da existência de um todo.

Vamos, a seguir, enunciar o enredo da história também em partes, fazendo as devidas aproximações com as estratégias produtivas da publicidade, até seu efetivo desfecho, como propomos.

\section{O homem é o meio da mensagem}

O conto, protagonizado pelo jovem Enrico, inicia-se com a sua chegada à sala de espera de uma "agência de publicidade", onde foi em resposta a um anúncio classificado que lera no jornal Corriere - "um trabalho fácil e bem remunerado", ideal para quem, como ele, queria se casar e não tinha dinheiro.

Não por acaso, enquanto aguardava ser chamado, o que só ocorreu duas horas depois, Enrico escolheu uma revista "ensebada" da pilha depositada numa mesa, para passar o tempo. E, já na entrada da história, temos um aspecto associado diretamente à trajetória da publicidade como um discurso, digamos, o primeiro, o discurso original da persuasão em prol do consumo.

Este aspecto é o meio pelo qual o jovem descobre que poderia se candidatar àquele tipo de "emprego", ainda obscuro para ele - um anúncio classificado, tipo de comunicação inaugural da atividade publicitária que, mais adiante, na Belle Époque francesa, vai também utilizar os cartazes de rua para a promoção de produtos e serviços. Os anúncios classificados, seguem, ainda hoje, uma espécie de retórica de empilhamento (CARRASCOZA; HOFF, 2009), ao textualizar a enumeração de ofertas e/ou qualidades daquilo que se divulga. Um exemplo é o seguinte classificado, citado por Gilberto Freyre 
(2010, p. 91) em seu livro O escravo nos anúncios de jornais brasileiros do século XIX, que tão bem se insere na discussão sobre o sentido do humano:

Vende-se uma escrava muito moça, bonita figura, sabe cozinhar e engomar e é uma perfeita costureira, própria para qualquer modista: na botica de Joaquim Ignácio Ribeiro Junior, na praça da Boa Vista.

Outro exemplo é este anúncio, um classificado de aluguel de imóvel, extraído de um jornal de São Paulo:

Paraíso, R\$ 3.500. Ótima localização! 105 m2, ensolarado, andar alto. Venha conhecer. Ref. 618062. Tel.: 3050-3322. M Baroni (FOLHA DE S. PAULO, 2014, p. 6).

Curiosamente, aquele é considerado o anúncio mais brilhante e "honesto" da história da publicidade, apresenta o empilhamento de características negativas (ou seriam realistas?) de sua "oferta". O classificado escrito, em 1900, pelo explorador Ernest Shackleton, em busca de homens para acompanhá-lo em sua expedição ao Polo Sul, diz:

Necessitam-se homens para viagem perigosa. Salários baixos, frio intenso, longos meses em completa escuridão, perigo constante, regresso duvidoso. Honra e reconhecimento em caso de êxito (MENNA BARRETO, 2004, p. 3).

Pois bem: Enrico é instado pelas informações empilhadas no anúncio a se candidatar, embora só vá saber do que se tratava aquele "trabalho" tão fácil - que não poderia nem ser chamado de um trabalho, mas de "uma prestação", "uma concessão" -, quando, finalmente, ele é atendido na agência. O que chama mais atenção no rapaz que o recebe não é o nome no crachá, Carlo Rovati, o cabelo cortado à escovinha e o corpo bronzeado e atlético, mas sua testa na qual está escrito, em caracteres azuis, "Férias na Savóia".

Rovati não atua tão somente como profissional da empresa, é também um dos próprios "divulgadores" do negócio que será proposto a Enrico, um intelectual orgânico, o "persuasor permanente" como o denominou Gramsci (2004, p. 53), e seu comportamento é obviamente constitutivo do habitus de seu campo (BOURDIEU, 1996).

Se a publicidade, com as suas mensagens, tem como intuito perante o público o fazer crer, é preciso que os membros de seu "exército, como Rovati, tenham antes se tornado crédulos das qualidades do produto anunciado. $\mathrm{O}$ funcionário, não por acaso, atende Enrico não apenas como um representante da empresa, mas com a autoridade de quem é a 
sua própria "voz": "Penso que não nos conhece, mas nos conhecerá logo, quer cheguemos a um acordo ou não. Somos pessoas agressivas, vamos diretamente ao que importa, sem rodeios" (LEVI, 2005, p. 320). Rovati, então, diz a Enrico que "quanto ao pagamento, o senhor julgará", e, depois de examinar o rosto do candidato, oferece-lhe uma quantia tão alta (4 milhões de liras), que o faz saltar da cadeira.

O narrador aprofunda o "fantástico" da cena, enunciando, por meio de Rovati, os detalhes expressivos do contrato que rege essa "nova técnica de promoção": 1) se Enrico aceitar a proposta, não será preciso pautar seu comportamento e suas opiniões em conformidade com o teor da mensagem anunciada - "eu, por exemplo, nunca estive na Savóia, nem de férias nem a trabalho, nem pretendo ir lá", diz o atendente; 2) O jovem pode vender ou apenas alugar sua testa - "e não sua alma", enfatiza Rovati; 3) A empresa propõe duas formas de contrato: por três anos - pela qual Enrico receberia o valor mencionado e por três meses - que evidentemente lhe renderia uma quantia bem inferior; 4) Em qualquer das opções, bastaria a Enrico passar no "centro gráfico", receber a inscrição, passar no caixa e retirar o cheque; 5) Ao fim do contrato, Rovati lhe explica, "o senhor passa aqui rapidamente, submete-se a uma pequena intervenção totalmente indolor e readquire o rosto de antes" (LEVI, 2005, p. 321).

Nesse ponto do enredo, como se o fazer crer da publicidade assumisse a cooptação se fosse instantâneo, se Enrico "comprasse" por impulso a proposta da empresa, Rovati afirma que o jovem não precisa decidir imediatamente, pode voltar para casa, pensar no assunto, trocar ideias com quem quiser, mas em uma semana deve retornar para fechar ou não o negócio.

Enrico, como se de volta à sua condição humana, pergunta se pode escolher a inscrição, e o funcionário lhe acena com um sim, embora dentro de certos limites: será apresentada uma lista de opções e ele fará a sua escolha.

Uma última pergunta ele faz a Rovati, dessa vez dentro da lógica mercantil, que pede ao produto algum diferencial, alguma singularidade: se ele seria o primeiro a ostentar aquele tipo de publicidade. O outro, lembrando-o de sua própria testa com a inscrição "Férias na Savóia", informa que já foram feitos 88 contratos na cidade. E, para fechar seu discurso persuasivo, Rovati se vale do argumento de urgência, tão comum nas campanhas publicitárias de varejo:

Portanto não tenha medo, o senhor não estará sozinho nem deverá dar muitas explicações. De acordo com as nossas previsões, dentro de um ano a publicidade frontal se tornará uma tendência em todos os centros urbanos, talvez até uma marca de originalidade e de prestígio pessoal, como o distintivo de um clube (Ibid., p. 322). 
Assim termina a primeira parte da história - de um lado Rovati, que representa as marcas, cujos produtos, como lembra Rocha (1990) retiram o humano de sua produção; do outro, Enrico, signo do homem que se estigmatiza pelo dinheiro para obtenção dos bens de consumo.

\section{A marca publicitária entre dois amores}

O narrador sinaliza com um espaço vazio o fim dessa primeira parte e o início da segunda, quando Enrico se retira do escritório e vai contar a Laura, sua noiva, sobre o "trabalho". Para seu espanto e desconforto, a moça não hesita nem um minuto em the recomendar que aceite a proposta. Laura lembra a Enrico que, com os 4 milhões, o problema da moradia já estaria resolvido, e se revela decidida a ampliar imediatamente o negócio do casal:

(...) os quatro milhões poderiam virar oito ou quem sabe dez, e aí se resolveria a questão dos móveis, do telefone, da geladeira, da lavadora e do carro. Dez como? Mas é óbvio! Ela também gravaria a inscrição, e um casal jovem, charmoso, com dois anúncios na testa complementares entre si, valeria certamente mais que a soma de duas cabeças desgarradas (Ibid., p. 322).

Nesse momento, o noivo, que não vê problema em ser "marcado" na testa, não pensa o mesmo em relação à sua companheira, como se, embora coisificado, visse nela um resto ainda de sua própria humanidade. Laura, com a "fronte límpida e tão pura" marcada como gado, não seria mais a mesma Laura - passaria, podemos afirmar, de sujeito a objeto como Enrico, objeto que ele, quanto a si, já não obsta impedir. Esses versos de Drummond (1984, p. 86), do poema já citado, dão conta de apreender seu estado: "Com que inocência demito-me de ser/ Eu que antes era e me sabia/ Tão diverso de outros, tão mim mesmo,/ Ser pensante sentinte e solitário/ Com outros seres diversos e conscientes/ De sua humana, invencível condição".

No entanto, assim se expressa o narrador, o jovem "se deixou convencer" pela noiva, e, dois dias depois, ambos se apresentam à agência de propaganda para negociar com Rovati. Esse ato se "deixar convencer" nos remete à posição de Baudrillard (2012), em seu já clássico estudo sobre a significação da publicidade, no qual afirma que ela se apoia na "lógica do Papai Noel" - sabemos que tal figura não existe, mas nos permitimos "acreditar" em sua existência para justificar nosso consumo na época de Natal.

Lipovetsky (2000, p. 7), em contraposição a teóricos apocalípticos, para os quais o desejo de consumir advém da manipulação publicitária, afirma que "a publicidade não 
consegue fazer com que se deseje o indesejável". Ou, em palavras ainda mais enfáticas: "só se pode seduzir alguém que já esteja predisposto a ser seduzido" (Ibid., p. 9). Em suma: ainda que um anúncio seja o mais sedutor possível, ele não será capaz de convencer o consumidor a renunciar à sua liberdade de escolha. A Enrico foi dada a possibilidade de escolher. E se ele ainda hesitava, a decisão incontinenti de Laura o levou, por fim, a segui-la.

Já na agência, os noivos, em negociação com Rovati, conseguem 9 milhões de liras pela inscrição dupla - o publicitário teria "apreciado até demais a testa de Laura" -, mas não tiveram muita escolha quanto à marca do produto a ser compartilhado, uma fábrica de cosméticos. $\mathrm{O}$ detalhe expressivo se materializa na forma de um lírio desenhado acima do nariz de ambos; na testa de Laura se escreve "Lilywhite para ela" e, na de Enrico, "Lilybrown para ele".

Essa situação ilustra, inclusive, uma das técnicas do marketing, que se materializa na chamada "promoção casada", pela qual duas empresas (uma produtora e outra distribuidora, por exemplo) se juntam para comercializar o mesmo bem de consumo, ou quando, numa mesma peça publicitária, faz-se a divulgação de distintas versões de um mesmo produto (um perfume para o público masculino, outro para o feminino, como no nosso caso).

O narrador, então, se detém em focar os problemas que o casal enfrenta depois da estampar na testa a mensagem da marca Lily e seu dêitico (o lírio). Enrico, foi obrigado a dar "um bom número de explicações" no escritório onde atuava. Como o próprio cânone do discurso publicitário, que enfatiza pontos positivos de uma mercadoria e omite os negativos, o jovem resolve contar a verdade, quer dizer, "a verdade quase pura": ele menciona a cifra de 9 milhões, mas não diz ser a soma do que ele e Laura haviam recebido, temendo que o acusassem de ter se vendido por pouco. Claro, houve quem apoiasse seu gesto e quem o desaprovasse. Contudo, seu constrangimento se encolhe, ao ver, semanas depois, sem que divulgasse o endereço da agência, um dos seus companheiros, Molinari, "sério e atento como sempre atrás da sua prancheta, com a seguinte inscrição na testa: 'Dentes saudáveis com Alnovol'” (LEVI, 2005, p. 323).

A publicidade assim se capilariza em todo e qualquer suporte que lhe possa servir como veículo de sua mensagem: assim, ela se disseminou pelas várias modalidades da mídia imprensa, como os cartazes, os jornais e, mais adiante, as revistas; seguiu, espraiando-se, pelas ondas do rádio, e desembocou nas telas de cinema e da televisão através dos filmes publicitários. No conto de Primo Levi, cada homem é visto como um espaço novo, reservado para a publicidade. Publicidade que, relembrando as palavras de Lipovetsky, não teria "seduzido" Molinari, se esse não estivesse predisposto para a sedução. 
Da mesma forma, Laura, que "havia concluído os estudos e ainda não trabalhava”, mantinha a sua discrição, mas se sentia observada nas lojas onde ia comprar peças do enxoval ou móveis, embora ninguém lhe perguntasse nada sobre a propaganda na fronte. Em casa, sua família não reagira mal, ao contrário, a mãe correra para se apresentar à agência, mas - eis aí outro aspecto da lógica publicitária! - recusaram a testa que ela oferecia porque "tinha muitas rugas para ser utilizável". O universo da produção é sórdido, mas o universo do consumo tem de ser idealizado. Daí as críticas de Toscani (1995, p. 13), cínico intelectual orgânico, para quem à publicidade dominante é o reino da felicidade, do sucesso, da juventude eterna, o paraíso sobre a Terra.

A trama dessa história, "fantástica", se desdobrará como uma autêntica ilustração da lei da oferta e procura que comanda as trocas mercantis - o que é escasso custa mais; o abundante é mais barato -, e, também, como exemplo da disseminação midiática do discurso publicitário. Vejamos: depois de poucos meses da viagem de lua de mel, o casal já não se sente mais desconfortável em público, pois

a agência devia ter feito um bom trabalho, ou talvez outras agências a imitaram, porque já não era raro encontrar pela rua ou nos ônibus indivíduos com a testa marcada. Na maioria eram rapazes ou garotas atraentes, muitos eram visivelmente imigrantes; no seu prédio, um outro jovem casal, os Massafra, trazia escrito na testa, em duas versões idênticas, o anúncio de uma certa escola profissionalizante por correspondência (LEVI, 2005, p. 323-324).

Aqui temos, exemplificado, o espalhamento da publicidade por meio de sua lógica sistêmica, ou pelo que Torres i Prat (2005) denomina de complexo comercial publicitário, que funcionaria como a matriz de uma fábrica de sonhos, feita para construir no imaginário social mundos idílicos. Nesse trecho da história, temos, igualmente, a preclara apresentação do perfil do público que, até pouco tempo, era quase o único "mostrado" pela publicidade dentro dos anúncios - os rapazes e garotas atraentes -, anúncios "vivos", no relato de Primo Levi.

Importante também apontar que, na lua de mel, Enrico e Laura levam no carro uma barraca para os pernoites, mas evitam campings organizados, fugindo dos olhares. É como se o veículo, pelo qual é difundido o consumo material dos perfumes Lilywhite e Lilybrown, operasse, ao menos no início, ao contrário de sua finalidade: por ser "humano", tentaria impedir o consumo simbólico (da publicidade), posto que qualquer indivíduo, ao cruzar com o casal, consumiria a mensagem publicitária marcada na testa deles. 
Canclini (1995) afirma que o consumo gera a sensação de pertencimento, sujeitos que consomem o mesmo produto se julgam ligados ao ideário do grupo. No entanto, podemos dizer que nos agentes da produção - mesmo se concorrentes - também esse sentimento está presente, sabe-se que as empresas costumam se unir em associações por segmento de atuação, além de compactuar com demais grupos pertencentes à sua cadeia produtiva. Como lembra Maffesoli (2000), os grupos, para sobreviver - no caso, as empresas - , fazem pactos entre si, fortalecendo a "ajuda-mútua".

No espaço de mediação das esferas da produção e do consumo, essa "empatia" também se dissemina, pois Enrico e Laura fazem amizade com o casal Massafra, começam a ir juntos ao cinema, a jantar na trattoria aos domingos. O narrador a descreve com precisão, ao realçar que os dois casais, no restaurante,

perceberam rapidamente que uma outra mesa, próxima à deles, era freqüentada por pessoas assinaladas e foi natural estabelecer contato e trocar confidências sobre os respectivos contratos, sobre as experiências precedentes, sobre as relações com o público e sobre os planos para o futuro (LEVI, 2005, p. 324).

Então, passado algum tempo, a multiplicação dos domínios publicitários se acelera. Enrico e Laura já não se sentiam mais tão sozinhos: nos cálculos do jovem, 1 cidadão em cada 30 trazia algum anúncio na testa. E as mensagens não se restringiam a produtos, mas também a causas individuais ou sociais: um jovem elegante ostentava no rosto "Johnson carrasco"; outro rapaz exibia "Ordem = Civilização"; um "trintão" trazia "Vote em branco"; duas gêmeas graciosas estampavam na testa, respectivamente "Viva o Milan" e "Força, Zilioli"; uma turma de alunos de uma escola ostentava a frase "Sullo, go home". E eis o "fantástico" se reproduzindo, como mímese, entre as crianças - posto que se tornara comum vê-las nas ruas, tendo na testa, rabiscados, com simples caneta, "vivas e abaixos, injúrias e palavrões".

O complexo comercial publicitário, com o advento da internet, esparrama-se de forma rizomática, como apontamos em nossa obra Do caos à criação publicitária. No conto de Primo Levi, Enrico e Laura passam a receber, a partir de então, a Gazeta dos Frontais, um jornal feito para homens-anúncios como eles: "naturalmente, setenta e cinco por cento de suas páginas eram dedicadas à publicidade, e mesmo os vinte e cinco restantes eram suspeitos" (loc. cit.).

Surgem novos negócios, seguindo a estratégia publicitária de atender a nichos de mercados - nesse caso, o público dos "frontais". Restaurante, acampamento e várias lojas passaram a lhes dar descontos. Anuncia-se também a fundação de um clube dos frontais. 
E, materializando a comunicação integrada do marketing contemporâneo, bem como reforçando a ideia de pertencimento, o Cristo no crucifixo de uma igreja visitada pelo casal traz escrito INRI na testa e não na tabuleta.

\title{
O desfecho demasiadamente "humano"
}

Mas o humano ainda persiste em Enrico e Laura: com a expansão dos "frontais", eles se sentem orgulhosos, são modelos pioneiros desse tipo de publicidade. A lei da procura e da oferta logo lhes mostrará que os preços haviam decaído: para a escrita de uma linha, por três anos, já não pagavam mais que 300 mil liras.

O que foi novidade ontem, já se tornou obsoleto hoje, como bem descreve o poema de Gregório Duvivier:

\author{
quando ela surgiu na minha janela \\ com seus dois metros e meio de pernas \\ cruzadas sobre a nossa senhora \\ de copacabana ensaboada de dove \\ esfoliação diária nunca mais deixei \\ o parapeito para não perdê-la de vista \\ escrevi poemas canções e cartas de \\ amor nunca respondidas até que uma tarde \\ enrugada rasgaram seu corpo em partes \\ iguais e trocaram no lusco-fusco \\ por um pacote gigante de wickbold (DUVIVIER, 2013, p. 65).
}

A mulher ensaboada de Dove logo dá lugar ao pão Wickbold. E assim se sucede nos espaços publicitários - e imaginários da sociedade.

Quando está para terminar o contrato de três anos, Laura descobre que está grávida. Vai, então, com Enrico propor uma renovação a Rovati, que oferece um valor irrisório para elogiarem "certos filminhos dinamarqueses". O casal recusa e desce para o centro gráfico da agência para "apagar" o lírio na testa que, no entanto, apesar das promessas feitas, continuará perceptível.

O desfecho da história continua na linhagem do fantástico, que assume, então, a ordem reprodutiva da publicidade: nasce um menino robusto e bonito, mas, inexplicavelmente, em sua testa vem escrito "Cavilhas Padronizadas". A produção de mensagens publicitárias atravessa não só a pele do homem, mas se infiltra, como se naturalizada, pela 
geração seguinte. O detalhe expressivo remete, durante o domínio nazista, à estrela de David levada ao corpo, obrigatoriamente, pelos judeus e por seus filhos.

Consagrando definitivamente o insólito da trama, o casal retorna à agência em busca de um contrato, mas Rovati, depois de fazer várias consultas, não localiza aquela razão social na Câmara de Comércio. Por isso, nada pode lhes oferecer, senão um bônus para que, no centro gráfico, o anúncio na testa do bebê seja apagado. Um apagamento que, sabemos, não é tão eficiente quanto o espalhamento da midiatização da publicidade.

O homem, contudo, pode se desetiquetar. Ou não? O psiquiatra Viktor Frankl, contemporâneo de Primo Levi, tendo também vivido no Lager, lembra-nos, em seu livro O homem em busca de sentido, que os objetos se determinam uns aos outros, mas o ser humano é seu próprio determinante:

Nos campos de concentração, naquele banco de provas, comprovamos e fomos testemunhas da atitude de nossos semelhantes: enquanto uns agiram como porcos outros se comportaram como santos. O homem goza de ambas potencialidades: elas dependem mais de suas decisões, do que das condições colocadas em jogo (FRANKL, 2007, p. 153).

Em "Escrito na testa", o humano ganha o estigma do desumano. O homem, tornado coisa, anuncia para os outros homens o seu sem sentido, quando deixa de determinar o seu próprio rumo.

\section{Referências}

ANDRADE, C. D de. Corpo. Rio de Janeiro: Record, 1984.

BAUDRILlARD, J. O sistema dos objetos. 5a. ed., São Paulo: Perspectiva, 2012.

BOURDIEU, P. As regras da arte. São Paulo: Companhia das Letras, 1996.

BROMBERT, V. Primo Levi e o canto de Ulisses. In: Em louvor de anti-heróis. São Paulo: Ateliê, 2001.

CANCLINI, N. G. Consumidores e cidadãos: conflitos multiculturais da globalização. Rio de Janeiro: UFRJ, 1995.

CARRASCOZA, J. A. ; HOFF, T. Ecos da literatura na publicidade brasileira nas primeiras décadas do século XX. In: CASTRO, G. G. da S. ; BACCEGA, M. A. (orgs.). Comunicação e consumo nas culturas locais e global. São Paulo: ESPM, 2009.

3 Tradução do autor. No original espanhol: "En los campos de concentración, en aquel laboratorio vivo, en aquel banco de pruebas, comprobamos y fuimos testigos de la actitud de nuestros camaradas: mientras unos actuaron como cerdos otros se comportaron como santos. El hombre goza de ambas potencialidades: de sus decisiones, y no tanto de las condiciones, según cuál de las dos pone en juego." 
DIAS, M. S. Primo Levi e o zoológico humano. In: LEVI, P. 71 contos. São Paulo: Companhia das Letras, 2005.

DOUGLAS, M. ; ISHERWOOD, B. O mundo dos bens. Rio de Janeiro: UFRJ, 2006.

DUVIVIER, G. Ligue os pontos: Poema de amor e big bang. São Paulo: Companhia das Letras, 2013.

FOLHA DE S. PAULO. Caderno de imóveis, 27 de fevereiro de 2014.

FREYRE, G. O escravo nos anúncios de jornais brasileiros do século XIX. 4. ed. São Paulo: Global, 2010.

GRAMSCI, A. Cadernos do cárcere. 4. ed. Rio de Janeiro: Civilização Brasileira, 2004, v. 2.

LEVI, P. 71 contos. São Paulo: Companhia. das Letras, 2005.

LIPOVETSKY, G. Sedução, publicidade e pós-modernidade. Revista FAMECOS. Porto Alegre, n.12, jul. 2000.

MAFFESOLI, M. O tempo das tribos: o declínio do individualismo nas sociedades de massa. 3. ed. Rio de Janeiro: Forense Universitária, 2000.

MENNA BARRETO, R. O copy criativo: 177 magnificos textos de propaganda (para ver se você finalmente aprende a redigir um). Rio de Janeiro: Qualitymark, 2004.

ORLANDI, E. P. Análise de discurso: princípios e procedimentos. 2.ed. Campinas: Pontes, 2000.

ROCHA, E. P. G. Magia e capitalismo: um estudo antropológico da publicidade. 2. ed. São Paulo: Brasiliense, 1990.

SLATER, D. Cultura do consumo e modernidade. São Paulo: Nobel, 2002.

TORRES I PRAT, J. Consumo, luego existo: Poder, mercado y publicidad. Barcelona: Icária, 2005.

TOSCANI, O. A publicidade é um cadáver que nos sorri. Rio de Janeiro: Ediouro, 1995.

WOOD, J. Como funciona a ficção. São Paulo: CosacNaify, 2011. 
